\title{
A Nursing Case Report: The Laryngectomy Patient Secondary to Pseudomonas aeruginosa Pneumonia with Conscious Disturbance
}

\author{
Jing Geng1, Chen Li ${ }^{2}$ \\ ${ }^{1}$ Department of Nursing, Medical School of Yangtze University, Jingzhou, China \\ ${ }^{2}$ The First Affiliated Hospital \& The First School of Clinical Medicine, Yangtze University, Jingzhou, China \\ Email: gengjing89@163.com
}

How to cite this paper: Geng, J. and Li, C. (2018) A Nursing Case Report: The Laryngectomy Patient Secondary to Pseudomonas aeruginosa Pneumonia with Conscious Disturbance. Yangtze Medicine, 2, 146-153. https://doi.org/10.4236/ym.2018.23015

Received: June 10, 2018

Accepted: August 27, 2018

Published: August 30, 2018

Copyright (c) 2018 by authors and Scientific Research Publishing Inc. This work is licensed under the Creative Commons Attribution International License (CC BY 4.0).

http://creativecommons.org/licenses/by/4.0/

\section{(c) () Open Access}

\begin{abstract}
The paper presents a description of the experience of the nursing for the Pseudomonas aeruginosa pneumonia patient with partial laryngectomy. The nursing of Pseudomonas aeruginosa pneumonia, conscious disturbance, electrolyte disorder, affection supports and mental nursing was provided in the process of the postoperative treatment. Our experience may provide useful insight for the nursing of laryngectomy patients secondary to pneumonia with conscious disturbance. A deeper knowledge about improving the quality of clinic special nursing for the partial or total laryngectomy patient is necessary, with the development of modern medical technologies and medicine.
\end{abstract}

\section{Keywords}

Laryngeal Carcinoma, Pseudomonas aeruginosa, Pneumonia, Conscious Disturbance, Nursing

\section{Introduction}

Laryngeal cancer (LC) is one of the most frequently diagnosed head and neck malignancies, causing 83 thousand deaths worldwide each year. In 2012, the highest age-standardized incidence rate of LC in Asia area was 6.3 per 100 thousand persons, respectively [1]. Currently, surgical operation is the most effective treatment. One tenth of perilaryngeal patients undergo partial or total laryngectomy [2]. A high incidence of postoperative complications occurred after partial or total laryngectomy [3]. Tracheostomal after laryngectomy causes the respiratory changing: respiratory mucosal warming, humidifying, filtering loss. And the risk of post-operative infection is usually related to the peri-operative 
exposure of the wound to commensal bacteria colonizing mucous membranes and skin [4]. Above all increase the rate of pulmonary infection [5]. It was reported that the incidence of pulmonary infection after laryngectomy was $1.4 \%$, Pseudomonas aeruginosa, Escherichia coli, Streptococcus pneumonia are the frequent pathogenic bacteria of pneumonia, of which Pseudomonas aeruginosa is the major pathogens [6] [7]. Therefore, all LC patients with postoperative tracheostomy would receive antibiotic prophylaxis with cephalosporin, aminoglycoside and metronidazole [8]. With the clinical abuse of the broad-spectrum antibiotics, the drug resistances are increased in Pseudomonas aeruginosa, and the incidence of Pseudomonas aeruginosa pneumonia is increasing these years. Elderly patients with pneumonia in early stage lack typical respiratory symptoms, $30 \%$ of who only have the symptom of acute disturbance of consciousness, shortness of breath and accelerated heart rate [9]. Above all, it will lead to the delay of treatment and care. Nurses play a critical role in patients' care throughout the pre- and postoperative period with special nursing for their safe transition back to society [10]. In this study, our purpose was to present our special nursing care of the laryngectomy patient secondary to Pseudomonas aeruginosa pneumonia with conscious disturbance for ENT nurses as a reference.

\section{Clinical Data}

A 71-year-old man had presented hoarseness during the past 1 year, visiting hospital in August, 2017. Pathological diagnosis was glottic cancer (T1N0M0). Cricohyoidoepiglottopexy (CHEP) was performed under generalanesthesia with perfect preoperative preparation. Fervescence occurred at the third day postoperatively, the oral temperature increasing from $38^{\circ} \mathrm{C}$ to $39.5^{\circ} \mathrm{C}$. Then conscious disturbance occurred at the 5th day; the Glasgow Coma Scale (GCS) scores were 12; be a purulent yellow-green expectoration; the skull CT scanning had no abnormality, but thorax CT diagnosed pulmonary inflammation and little pleural effusion; blood pictures were abnormal (blood calcium $1.6 \mathrm{mmol} / \mathrm{L}$, blood kalium $3.0 \mathrm{mmol} / \mathrm{L}$, blood sodium $122 \mathrm{mmol} / \mathrm{L}$ ). Phlegm cultivation before use medicine was chosen firstly, then adjust antibiotic based on phlegm cultivation results (Pseudomonas aeruginosa and klebsiella species infection) and drug sensitivity test results (Amikacin). Therapeutic Methods were anti-inflammatory, temperature decreasing, eliminating phlegm, rehydration, monitoring of blood routine examination, hepatic and renal functions, electrolytes, blood glucose and others. The recovery of consciousness was at the 9th day postoperatively, with the GCS score 15. The patient tried to take food, oral temperature recovery to normal, but occurred irritating cough at the 10th day. Classifications of levels of bedside water-swallowing test (WST) are level $1-5$. The result of $30 \mathrm{ml}$ bedside water-swallowing test was level 4 . Then, the swallow function returned to level 3 in 17th days, the vital signs were all stable, thorax CT and phlegm cultivation results returned normal. The patient discharged hospital with metal tracheal cannula. Postoperative special nursing care of the patient is in Table 1. 
Table 1. Postoperative special nursing care of the patient.

\begin{tabular}{|c|c|c|}
\hline $\begin{array}{l}\text { Postoperative } \\
\text { days }\end{array}$ & $\begin{array}{l}\text { Abnormal symptom } \\
\text { nursing observation }\end{array}$ & Nursing measures \\
\hline \multirow[t]{3}{*}{5} & Fervescence & Oral temperature $\left(38^{\circ} \mathrm{C}-39.5^{\circ} \mathrm{C}\right)$ \\
\hline & Conscious disturbance & Blood sample was taken; GCS score 12 \\
\hline & $\begin{array}{l}\text { Purulent yellow-green } \\
\text { expectoration }\end{array}$ & $\begin{array}{l}\text { Sputum Aspiration; Turning over and Patting the Body; } \\
\text { Phlegm cultivation; drug sensitivity test results }\end{array}$ \\
\hline 9 & $\begin{array}{l}\text { Choking cough } \\
\text { when taking food }\end{array}$ & $\begin{array}{l}\text { The } 30 \mathrm{ml} \text { bedside water-swallowing test (level 4); } \\
\text { GCS score } 15\end{array}$ \\
\hline 17 & $\begin{array}{l}\text { Decrease of cough } \\
\text { during food taking }\end{array}$ & The $30 \mathrm{ml}$ bedside water-swallowing test (level 3) \\
\hline
\end{tabular}

\section{Nursing Focus}

\subsection{The Nursing of Pseudomonas aeruginosa Pneumonia}

The symptom of mucous membrane dryness, weakness of cough occurred in the early postoperative period. Pseudomonas aeruginosa pneumonia caused fever, delirium, purulent yellow-green expectoration, oxygen saturation down. Besides humid sputum suction, the pertinence measure to the symptom existed is: 1) Monitoring of vital signs was immediately carried out, blood pressure (108/55 $\mathrm{mmHg}$ ), heart rate (>128 beats/min), the blood oxygen saturation (93\%). Mask oxygen-inspiration $(6-8 \mathrm{~L} / \mathrm{min}$ ) with tracheotomy tubes and intravenous fluids supplement had kept vital signs normal. 2) In early postoperative stage, the great dose of cefuroxime antibiotics was used to prevent the infection of Haemophilus influenzae and Meningococcus, invalid therapy for Pseudomonas aeruginosa and Staphylococcus aureus infection. Basis for phlegm cultivation results (Pseudomonas aeruginosa and klebsiella species infection) and drug sensitivity test results, the optimal dose of Amikacin and Imipenem-Cilastain was used. Meanwhile, the adverse drug reaction (ADR) was being monitored for 6 days continuously, like hepatic and renal function, hematuria and proteinuria, auditory function. 3) The color, characteristics, quantity of phlegm were closely observed and recorded every day. Once the infection of cervical incision, oral and nasal mucosa occurred, the specimens were taken to test pathogenic bacteria. 4) Moist skin were easy to be damaged with heavy perspiration caused by the fever $\left(38^{\circ} \mathrm{C}\right.$ $-39.5^{\circ} \mathrm{C}$ ), especially the cervical pressure bandaging skin, the nasal entrance skin of nasogastric tube, electrode slices paste skin. Observation of skin humidity and skin temperature per hour can avoid complications. According to the grade of sputum density (level-1 mucoid, level-2 mucopurulent, level-3 purulent), the characteristics of sputum were changed from purulent (level 3) to mucoid (level 1) and no other complications occurred.

\subsection{The Nursing of Conscious Disturbance}

Hypoimmunity after surgical injury may be a main cause of bacterial infection in the elderly patients. And the bacterial toxins and imbalance of water-electrolyte 
were the main factors of conscious disturbance. The change tendency of postoperative GCS scores was as follows (Figure 1). Sudden confusion (GCS score 12) appeared in the postoperative 5th day. GCS assessed 3 parts: best eye opening response (To speech-call the patient's name); best verbal response (Confused about time and place orientation); motor response (Localise to pain). Pupil sizes were normal, but the pupillary light reflex delayed. The skull CT scanning had no abnormality. Considering that conscious disturbance might be caused by Pseudomonas aeruginosa pneumonia. The level of consciousness could reflect the severity of pneumonia in some degree [11]. Therefore, the assessment of consciousness level played an important role for mastering the progress of disease. Communication with the family members was helpful for disease evaluation. During continued treatment, GCS was 13 scores, with best eye opening response (Spontaneous-observed before approaching the patient); best verbal response (confused about time and place orientation); motor response (Localise to pain) in the 7th day. Spontaneous motor activity like hand gestures increased and sleep time reduced. The pupillary light reflex recovered in the normal subject, GCS score 14 appearing to be confused about place orientation in the 8th day, encouraging the patient to communicate with written forms. The time of consciousness recovery was in the 9th day and GCS score 15 was assessed to be normal.

\subsection{The Nursing of Electrolyte Disorder}

The common cause of delirium is electrolyte disturbance, like hyponatremia, hypokalemia, hypeochloremia in the elderly patients [12]. The level of blood calcium $(1.6 \mathrm{mmol} / \mathrm{L})$, blood kalium $(3.0 \mathrm{mmol} / \mathrm{L})$ and blood sodium $(122$ $\mathrm{mmol} / \mathrm{L}$ ) was lower than normal value, and the possible causes were the body electrolytes loss from hyperthermia and the severity of energy expenditure. The close observation of patients was kept as charge nurses. The main symptoms of hyponatremia are hypodynamia, poor appetite, sleepiness; the main symptoms of hypokalemia are myasthenia, cardiac arrhythmia; the main symptoms of hypocalcemia are muscular spasm and clonus. Dynamical electrocardiographic

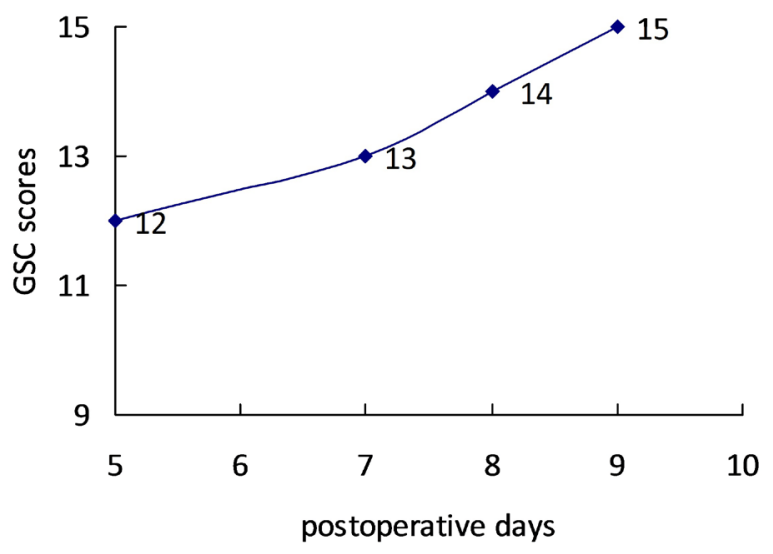

Figure 1. The variation curve of postoperative GSC scores. 
monitoring was carried out, cardiac function including the heart rate, cardiac rhythm, waves cycles followed. Meanwhile, the patient's chief complaints can reflect the disease change, muscular tension was evaluated with modified Ashworth scale, muscle strength assessed with Lovett grading method. The patient complained occasional peripheral numbness of mouth, considered of hypocalcemia. Electrolyte in blood was measured immediately. With the correction of electrolyte disturbance, consciousness recovery occurred.

\subsection{Affection Supports and Mental Nursing}

Cheryl Bressler suggested that patients' active participant in the pre-operative period was important for the successful recovery [10]. Thus, the patient was arranged to have a pre-operative visit by a return-visit patient who has achieved a successful means of communication after the CHEP. They discussed their concerns and also identified post-operative communication methods. One study [3] indicated that psychological intervention is beneficial in improving life quality in patients with laryngeal cancer after surgery. Pre-operative psychological nursing measures included encouraging patients, and family support. It is difficult to accept the fact of losing the ability to speak after operation. Therefore, it is important for nurses to provide delicate care and encourage the patient to express himself. Instructing the patient to express himself with magic slates, writing materials, pictorial guides or hand signals had resulted in less anxiety and depression. Expressing the feeling, thoughts and aspiration with languages would last a long term in the period of pronunciation practice. The patient had been taught how to clean and sterilize the inner cannula, which would help to increase self-care capability before discharge. To develop the active states of mind to face the disease, building up self-confidence for high-quality life. Simultaneously, the patient's families provided much participation and support in the performance of comfort care mentally, like more concerns, medical expenditure support, Unhealthy Emotion Self-control. The final purpose of the nurse and family was to make the patient feel more psychological comfort.

\section{Conclusions}

The laryngectomy patients are faced with tremendous physical and emotional injuries. Especially, the complication with Pseudomonas aeruginosa pneumonia occurred delays the recovery in the post-operative period. Nurses play a vital role in providing the patients with education, and special nursing care, so they will have a safe transition back into society.

\subsection{Intensive Nursing Care}

It is suggested that head and neck surgery patients are admitted to Critical Care Unit (CCU) for 24-hour intensive nursing care in order to allow for airway oedema to stabilize and facilitate safe extubation [13]. The elderly patients' pulmonary ventilation function was damaged caused by pneumonia, then it would 
result in hypoxemia. And in acute infection period, toxic encephalopathy and electrolyte disturbance will lead to delirium. Even as Marcantonio found [12] that postoperative delirium occurred in 117 (9\%) of the 1341 patients studied; age 70 years or older, poor cognitive status and poor functional status were independent correlates. Therefore, once the symptoms of fever (above $38.5^{\circ} \mathrm{C}$ ), mucus hypersecretion, the sputum nature changing and delirium occur for the early postoperative period, the nurses communicate with doctors immediately for the treatment. The characteristic symptoms of delirium are conscious disturbance, emotional disturbance, dysarthria and disorientation [14]. Close observation of patient's consciousness state with the Glasgow score scale is especially important every day. It is closely related to the accuracy of clinical nurses' subjective assessment. Above all, the safety of nursing head and neck cancer patients on a specialized ward with adequately trained nursing staff has already been evidenced [15].

\subsection{To Prevent the Occurrence of Complications}

Now the emergence of resistance is a major public health problem, and the excessive antibiotics use must be eliminated [4]. The possibility of Pseudomonas aeruginosa being the causative agent should be considered in patients presenting with lung empyema, especially in immunocompromised patients [16]. Nosocomial infections caused by Pseudomonas aeruginosa are difficult to treat because of the low permeability of its outer membrane and its remarkable ability to acquire further resistance to antibiotics [17]. Fever (above $38.5^{\circ} \mathrm{C}$ ) and energy intake deficiency caused water-electrolyte imbalance of varied degrees which increased the risk of infection, and poor functional status were independent correlates of postoperative delirium [12]. Nurses should give priority to prevention of accompanies and emphasize on basic nursing measures, like early out of bed activity, turning over, patting the back, sputum aspiration timely, ample gastric feeding, consciousness state assessment. Due to language function loss, the observation of disease condition is even more important for the therapy. Postoperative laryngeal cancer patients secondary to Pseudomonas aeruginosa pneumonia with conscious disturbance occur in a relatively small amount. We collected the clinical data and nursing measures in the report, hoping to provide reference for nursing colleagues.

\section{Limitation}

The case nursing of laryngectomy Patient Secondary to Pseudomonas aeruginosa pneumonia with Conscious Disturbance is rare in clinic but severe complication, being increasingly recognized recently. Thus, our study just discusses the experiences and measures of special nursing care that others could learn from it. Unfortunately, limitation is that the information offered in this document does not offer any additional information, any medically trained person looking at Lab values would do. 


\section{Conflicts of Interest}

The authors declare no conflicts of interest regarding the publication of this paper.

\section{References}

[1] World Health Organization (2012) International Agency for Research on Cancer. Globocan 2008: Cancer Incidence and Mortality Worldwide in 2012. http://globocan.iarc.fr/

[2] Kotake, K., Suzukamo, Y., Kai, I., Iwanaga, K. and Takahashi, A. (2016) Social Support and Substitute Voice Acquisition on Psychological Adjustment among Patients after Laryngectomy. European Archives of Oto-Rhino-Laryngology, 274, 1-9. https://doi.org/10.1007/s00405-016-4310-0

[3] Prasad, V.B., Mallick, S., Upadhyay, A.D. and Rath, G.K. (2017) Systematic Review and Individual Patient Data Analysis of Pediatric Head and Neck Squamous Cell Carcinoma: An Analysis of 217 Cases. International Journal of Pediatric Otorhinolaryngology, 92, 75-81. https://doi.org/10.1016/j.ijporl.2016.11.005

[4] Scotton, W., Cobb, R., Pang, L., Nixon, I., Joshi, A., Jeannon, J.P., Oakley, R., French, G., Hemsley, C. and Simo, R. (2012) Post-Operative Wound Infection in Salvage Laryngectomy: Does Antibiotic Prophylaxis Have an Impact? European Archives of Oto-Rhino-Laryngology, 269, 2415-2422. https://doi.org/10.1007/s00405-012-1932-8

[5] Du, Q., Ji, W.Y., Guan, C. and Xu, Q.Y. (2006) Prognostic Factors Identified by Cox Multivariate Analysis of Surgically Treated 1018 Laryngeal Cancer Patients. Chinese Journal of Oncology, 28, 211-213. https://doi.org/10.3760/j.issn:0253-3766.2006.03.013

[6] Jiang, L.J., Wang, D.F. and Wang, L. (2005) The Etiology and Bacterial Resistance of Aged Patients with Hospital Acquired Pneumonia. Practical Geriatrics, 19, 198-200. https://doi.org/10.3969/j.issn.1003-9198.2005.04.012

[7] Herranz, J . (2000) Complications after Total Laryngectomy in Non-Radiated Laryngeal and Hypopharyngeal Carcinomas. Otolaryngol Head Neck Surgery, 122, 892.

[8] Sotirović, J., Baletić, Š.V.N., Pavićević, L., Bijelić, D., Erdoglija, M., Perić, A. and Soldatović, I. (2015) Risk Factors for Surgical Site Infection in Laryngeal Cancer Surgery. Acta Clinica Croatica, 54, 57.

[9] Fang, M.J. and He, F.F. (1999) Clinical Exploration of Conscious Disturbance in the Elderly. Chinese Journal of Gerontology, 19, 309. https://doi.org/10.3969/j.issn.1005-9202.1999.02.021

[10] Bressler, C. (1999) Post-Operative Care of the Laryngectomy Patient. Perspectives, 2, 1-8.

[11] Masuda, N., Sakagawa, E. and Ohya, S. (1995) Outer Membrane Proteins Responsible for Multiple Drug Resistance in Pseudomonas aeruginosa. Antimicrobial Agents and Chemotherapy, 39, 645-649. https://doi.org/10.1128/AAC.39.3.645

[12] Marcantonio, E.R., Goldman, L., Mangione, C.M., Ludwig, L.E., Muraca, B., Haslauer, C.M., Donaldson, M.C., Whittemore, A.D., Sugarbaker, D.J., Poss, R. and Et, A. (1994) A Clinical Prediction Rule for Delirium after Elective Noncardiac Surgery. The Journal of the American Medical Association, 271, 134-139. https://doi.org/10.1001/jama.1994.03510260066030

[13] Walijee, H., Morgan, A., Gibson, B., Berry, S. and Jaffery, A. (2016) Critical Care 
Admissions Following Total Laryngectomy: Is It Time to Change Our Practice? International Journal of Otolaryngology, 2016, 1-8.

https://doi.org/10.1155/2016/8107892

[14] Kim, S.J., Kim, J.Y., Ryu, C.G., Seo, J.H., Kim, J.N. and Sung, W.Y. (2011) A Case Report of the Delirium Accompained Wi Syndrome during the Treatment of Pneumonia. Journal of Oriental Neuropsychiatry, 22, 71-83.

https://doi.org/10.7231/JON.2011.22.2.071

[15] To, E.W., Tsang, W.M., Lai, E.C. and Chu, M.C. (2002) Retrospective Study on the Need of Intensive Care Unit Admission after Major Head and Neck Surgery. Anz Journal of Surgery, 72, 11-14. https://doi.org/10.1046/j.1445-2197.2002.02285.x

[16] Chen, H.W., Zheng, J.Q. and Lin, T.Y. (2012) Fulminant Lobulated Lung Empyema Caused by Pseudomonas aeruginosa. Revista Chilena De Infectologia, 29, 114. https://doi.org/10.4067/S0716-10182012000100020

[17] Shang, D.J., Meng, X., Zhang, D.D. and Kou, Z.R. (2017) Antibacterial Activity of Chensinin-1b, a Peptide with a Random Coil Conformation, against Multiple-Drug-Resistant Pseudomonas aeruginosa. Biochemical Pharmacology, 143, 65-78.

https://doi.org/10.1016/j.bcp.2017.07.017 